\title{
Quantitative Study of Insulin Secretion and Clearance in Normal and Obese Subjects
}

\author{
K. S. Polonsky, B. D. Given, L. Hirsch, E. T. Shapiro, H. Tillil, C. Beebe, J. A. Galloway, \\ B. H. Frank, T. Karrison, and E. Van Cauter \\ The University of Chicago, Pritzker School of Medicine, Chicago, Illinois 60637; Eli Lilly Laboratories, Indianapolis, Indiana 46285; \\ and The Institute of Interdisciplinary Research, Free University of Brussels, B-1070 Belgium
}

\section{Abstract}

The secretion and hepatic extraction of insulin were compared in 14 normal volunteers and 15 obese subjects using a previously validated mathematical model of insulin secretion and rate constants for $\mathbf{C}$-peptide derived from analysis of individual decay curves after intravenous bolus injections of biosynthetic human C-peptide. Insulin secretion rates were substantially higher than normal in the obese subjects after an overnight fast $\left(86.7 \pm 7.1\right.$ vs. $50.9 \pm 4.8 \mathrm{pmol} / \mathrm{m}^{2}$ per $\mathrm{min}, P<0.001$, mean \pm SEM), over a $24-h$ period on a mixed diet $(279.6 \pm 24.2$ vs. $145.8 \pm 8.8 \mathrm{nmol} / \mathrm{m}^{2}$ per $24 \mathrm{~h}, P<0.001$ ), and during a hyperglycemic intravenous glucose infusion (102.2 \pm 10.8 vs. $57.2 \pm 2.8 \mathrm{nmol} / \mathrm{m}^{2}$ per $\left.180 \mathrm{~min}, P<0.001\right)$. Linear regression analysis revealed a highly significant relationship between insulin secretion and body mass index.

Basal hepatic insulin extraction was not significantly ilifferent in the normal and obese subjects $(53.1 \pm 3.8$ vs. $51.6 \pm 4.0 \%$ ). In the normal subjects, fasting insulin did not correlate with basal hepatic insulin extraction, but a significant negative correlation between fasting insulin and hepatic insulin extraction was seen in obesity $(r=-0.63, P<0.02)$. This finding reflected a higher extraction in the six obese subjects with fasting insulin levels within the range of the normal subjects than in the nine subjects with elevated fasting insulin concentrations ( $61 \pm 3$ vs. $45 \pm 6 \%, P<0.05)$.

During the hyperglycemic clamp, the insulin secretion rate increased to an average maximum of 6.2-fold over baseline in the normal subjects and 5.8-fold in the obese subjects. Over the same time, the peripheral insulin concentration increased 14.1-fold over baseline in the normals and 16.6-fold over baseline in the obese, indicating a reduction in the clearance of endogenously secreted insulin. Although the fall in insulin clearance tended to be greater in the obese subjects, the differences between the two groups were not statistically significant.

Thus, under basal, fasting conditions and during ingestion of a mixed diet, the hyperinsulinemia of obesity results predominantly from increased insulin secretion. In patients with more marked basal hyperinsulinemia and during intense stimulation of insulin secretion, a reduction in insulin clearance may contribute to the greater increase in peripheral insulin concentrations that are characteristic of the obese state.

Address correspondence to Dr. Polonsky, University of Chicago, Dept. of Medicine, Box 435, 5841 S. Maryland Ave., Chicago, IL 60637. 1987.

Received for publication 6 April 1987 and in revised form 30 July

J. Clin. Invest.

(C) The American Society for Clinical Investigation, Inc.

0021-9738/88/02/0435/07 \$2.00

Volume 81, February 1988, 435-441

\section{Introduction}

Hyperinsulinemia is a common finding in obesity (1-5). This abnormality could result from an increase in insulin secretion, a decrease in insulin clearance, particularly hepatic insulin extraction, or a combination of these two factors (1-7). The literature is divided on which mechanism is predominant. The inability to resolve the controversy relates in large measure to the fact that current techniques do not allow hepatic insulin extraction to be accurately measured in humans by noninvasive techniques (8).

In the present study, pancreatic insulin secretion rates were derived from peripheral concentrations of $\mathrm{C}$-peptide using a two-compartment model of C-peptide kinetics (9), which we have previously validated in animal and human experiments $(10,11)$. The use of this technique allowed us to compare insulin secretion in a group of normal weight and obese subjects under basal conditions, during 24-h sampling on a mixed diet and during a hyperglycemic clamp. Basal hepatic insulin extraction was calculated and the relationship between the insulin secretory rate and peripheral insulin concentrations was explored.

\section{Methods}

\section{Subjects}

Studies were performed in 14 normal volunteers and 15 obese subjects who did not have a personal or family history of diabetes. The normal and obese groups were well matched for age $(38.5 \pm 3.7 \mathrm{vs.} 35.8 \pm 2.8 \mathrm{yr}$, $P<0.001$ ) and sex ( 7 male, 7 female vs. 10 female, 5 male) and differed significantly only in parameters of obesity, namely weight (70.1 vs. $105.7 \pm 6.6 \mathrm{~kg}, P<0.001)$, body mass index $(23.0 \pm 0.5$ vs. $37.0 \pm 1.9$ $\left.\mathrm{kg} / \mathrm{m}^{2}, P<0.001\right)$, and percent ideal body weight $(102.6 \pm 2.5 \mathrm{vs}$. $167.5 \pm 8.6 \%, P<0.001$ ). All studies were performed in the Clinical Research Center of the University of Chicago. The protocol was approved by the Institutional Review Board and all subjects gave written informed consent.

\section{Study protocol}

Intravenous bolus injections of C-peptide and insulin. After a 10-h overnight fast, subjects received intravenous bolus injections of biosynthetic human C-peptide (BHCP) ${ }^{1}(150 \mu \mathrm{g})$ and insulin (1.5 U Humulin R; Eli Lilly \& Co., Indianapolis, IN) along with a constant infusion of somatostatin (Bachem Inc., Torrance, CA, $500 \mu \mathrm{g} / \mathrm{h}$ ) to suppress endogenous insulin secretion. The details of this protocol have previously been described (10). In this and subsequent studies, the hand with the sampling catheter was maintained in a heating blanket to ensure arterialization of the venous sample.

Experimental protocol for the measurement of endogenous insulin secretion. After a 10-h overnight fast, samples were drawn at 15-30min intervals beginning at 0600 for a total of $24 \mathrm{~h}$. During this time,

1. Abbreviation used in this paper: BHCP, biosynthetic human C-peptide. 
the subjects consumed a standard diet consisting of $30 \mathrm{cal} / \mathrm{kg}$ comprised of $50 \%$ carbohydrate, $15 \%$ protein, and $35 \%$ fat. $20 \%$ of total calories were eaten at breakfast and $40 \%$ with lunch and dinner, respectively. The relative proportions and type of food were held constant. At the completion of the 24-h sampling study, glucose was infused intravenously to raise the plasma glucose concentration acutely to 300 $\mathrm{mg} / \mathrm{dl}$. The glucose infusion rate was then varied to maintain the plasma glucose concentration at this level for a total of $180 \mathrm{~min}$, adjustments being made at 2-5-min intervals based on the plasma glucose concentration. Insulin and C-peptide concentrations were measured every 15 min throughout the study.

Sample collection and analytical techniques. Blood samples for insulin were allowed to clot at room temperature and the serum was stored at $-20^{\circ} \mathrm{C}$ until assayed. C-peptide and glucose samples were drawn into tubes at $4^{\circ} \mathrm{C}$ containing 500 kallikrein inhibitor units $/ \mathrm{ml}$ trasylol and $1.2 \mathrm{mg} / \mathrm{ml}$ EDTA. Plasma was separated immediately and stored frozen until assayed.

Serum insulin was assayed by a double antibody technique (12). Plasma glucose was measured with a glucose analyzer (Yellow Springs Instrument Co., Yellow Springs, $\mathrm{OH}$ ). Human C-peptide immunoreactivity in plasma was measured as previously described (13). BHCP and ${ }^{125} \mathrm{I}-\mathrm{Tyr}-\mathrm{BHCP}$ were used as assay standard and tracer, respectively (14).

\section{Data analysis}

Derivation of endogenous pancreatic insulin secretion rates. A twocompartment model was used to derive insulin secretion rates from peripheral C-peptide concentrations. This model assumes that C-peptide distributes into a central and a peripheral compartment. The central compartment from which sampling occurs consists of the plasma and tissues in rapid equilibration with plasma. $\mathrm{K} 1$ and $\mathrm{K} 2$ are the fractional rate constants that describe the movement of $\mathrm{C}$-peptide from the central to the peripheral compartments and back again. $\mathrm{K} 3$ is the rate constant that describes the irreversible metabolism of $\mathrm{C}$-peptide which is assumed to occur from the central compartment. We have demonstrated that this model allows accurate estimates of insulin secretion rates to be derived even under non-steady state conditions (10, 11). This approach was applied in the present study as follows: Model parameters of $\mathrm{C}$-peptide were derived in each subject by analysis of individual C-peptide decay curves as previously described (10). The parameters included the fractional rate constants $\mathrm{K} 1, \mathrm{~K} 2$, and $\mathrm{K} 3$ and the C-peptide volume of distribution, as well as the plasma half-lives and the metabolic clearance rate of $\mathrm{C}$-peptide. Production rates of C-peptide (and, therefore, insulin) were then obtained by solving the equations of Eaton (9) for data collected during the 24-h sampling and hyperglycemic clamp studies. A robust, locally weighted regression procedure described by Cleveland (15) was used to obtain a smooth representation of the $\mathrm{C}$-peptide concentration curves. The individual C-peptide kinetic parameters were then substituted into the Eaton equations to derive the $\mathrm{C}$-peptide and insulin secretion rates by a procedure termed deconvolution.

Using these methods, the secretion rate of insulin was derived under three experimental conditions: $(i)$ the basal insulin secretory rate, standardized for body surface area and expressed in picomoles per $\mathrm{m}$ squared per minute, was estimated at the mean secretory rate between 0600 and 0900 , i.e., during the 3-h-interval preceding breakfast; (ii) the 24-h insulin secretion was estimated as the area under the 24-h profile of secretion rates and was expressed as nanomoles per $\mathrm{m}$ squared per $24 \mathrm{~h}$; and (iii) the total secretory responses to intravenous glucose measured during the hyperglycemic clamp study were calculated as the area under the corresponding secretion curve and expressed as nanomoles per $\mathrm{m}$ squared per $180 \mathrm{~min}$.

Metabolic clearance rate of insulin. The metabolic clearance rate of insulin was derived from the insulin decay curves as previously described (16).

Hepatic insulin extraction. Under basal steady state conditions, the posthepatic delivery rate of insulin was calculated, in each subject, as the product of the individual mean insulin concentrations during the 3-h prebreakfast study period and the metabolic clearance rate multiplied by the body surface area. Since insulin secretion was simultaneously measured in each subject, it was possible to calculate basal hepatic insulin extraction according to the following formula: hepatic extraction $(\%)=($ secretion rate-post hepatic delivery rate $) /($ secretion rate) $\times 100$.

This approach to the measurement of hepatic insulin extraction is valid only under steady state conditions. To gain insight into the relationship between insulin secretion and the peripheral insulin concentration during the 24-h sampling and hyperglycemic clamp studies, the ratio of the area under the insulin secretion curve (picomoles per minute) and the area under the peripheral insulin concentration curve (picomoles per milliliter) was calculated. The units of this ratio are milliliters per minute, and since it relates insulin secretion to peripheral insulin concentrations, it is a measure of endogenous insulin clearance.

Statistical analysis. The significance of group differences was evaluated by the two-sample $t$ test unless otherwise stated. Pearson correlation coefficients were calculated to assess the degree of association between variables, and linear regression analysis was used to describe the relationship between insulin secretion and body mass index. Multiple variables were compared using multivariate analysis of variance. The C-peptide decay curves were analyzed as previously reported (17). Values are reported as mean \pm standard error of the mean. Differences were regarded as statistically significant if the corresponding $P$ value was $\leq 0.05$. All statistical analyses were performed using the statistical analysis system (Version 6; SAS Institute, Cary, NC).

\section{Results}

Decay curves of $C$-peptide. Each decay curve was resolved into the sum of two exponentials by nonlinear least-squares regression analysis allowing the kinetics of C-peptide to be individually defined. In the normal volunteers, the half-disappearance times of each exponential were $4.6 \pm 0.2$ and $30.6 \pm 0.8 \mathrm{~min}$, respectively, and the metabolic clearance rate of the injected C-peptide was $128.3 \pm 6.5 \mathrm{ml} / \mathrm{m}^{2}$ per $\mathrm{min}$. In the normal subjects, the parameters for a two-compartment model were as follows: $\mathrm{K}_{1}=0.050 \pm 0.004, \mathrm{~K}_{2}=0.045 \pm 0.002$, and $\mathrm{K}_{3}$ $=0.058 \pm 0.001 \mathrm{~min}^{-1}$, and distribution volume equals $2,226 \pm 84 \mathrm{ml} / \mathrm{m}^{2}$. The corresponding values in the obese subjects were not significantly different from normal $(P<0.2)$ by multivariate analysis of variance.

Metabolic clearance rate of insulin. The metabolic clearance rate of insulin derived from the decay curve after its bolus injection was not significantly different in the normal $\left(401.8 \pm 20.0 \mathrm{ml} / \mathrm{m}^{2}\right.$ per $\left.\mathrm{min}\right)$ and obese subjects $(410.4 \pm 34.8$ $\mathrm{ml} / \mathrm{m}^{2}$ per $\left.\min , P<0.8\right)$.

Insulin, $C$-peptide, and glucose concentrations. Insulin, Cpeptide, and glucose concentrations measured under basal fasting conditions, over the $24-\mathrm{h}$ period on a mixed diet and during the hyperglycemic clamp, are shown in Table I and Fig. 1. Although the average basal and 24-h glucose concentrations did not differ in the normal and obese subjects, both basal and 24-h insulin and C-peptide concentrations were significantly greater in the obese group. During the hyperglycemic clamp, glucose levels of $299.0 \pm 1.2$ and $299.6 \pm 0.8 \mathrm{mg} / \mathrm{dl}$ were achieved in the normal and obese groups, respectively. In this study, insulin and C-peptide concentrations were also significantly higher in the obese compared with the normal subjects.

Insulin secretion rates. Absolute insulin secretion rates were significantly higher in the obese subjects under all three experimental conditions. Even after correction for body surface area, the obese subjects secreted approximately twice as 
Table I. Mean Values ( \pm SEM) of Insulin, C-Peptide, Glucose, and Insulin Secretion Under Basal Conditions*

\begin{tabular}{lccl}
\hline & Normal & Obese & $P<$ \\
\hline Basal period (mean over a & & & \\
$\quad$ 3-h period) & & & \\
Insulin $(\mu \mathrm{U} / \mathrm{ml})$ & $8.2 \pm 0.5$ & $15.9 \pm 2.2$ & 0.003 \\
C-peptide $(\mathrm{pmol} / \mathrm{ml})$ & $0.43 \pm 0.04$ & $0.67 \pm 0.07$ & 0.005 \\
Glucose $(\mathrm{mg} / \mathrm{dl})$ & $95.5 \pm 1.5$ & $95.3 \pm 3.3$ & 0.95 \\
Secretion $\left(\mathrm{pmol} / \mathrm{m}^{2}\right.$ per $\left.\mathrm{min}\right)$ & $50.9 \pm 4.8$ & $86.7 \pm 7.1$ & 0.001 \\
24-h period with three & & & \\
$\quad$ mixed meals & & & \\
Insulin & $24.1 \pm 2.1$ & $62.9 \pm 10.7$ & 0.003 \\
C-peptide & $0.91 \pm 0.09$ & $1.58 \pm 10.7$ & 0.001 \\
Glucose & $108.0 \pm 1.8$ & $109.9 \pm 1.6$ & 0.5 \\
Secretion $\left(\mathrm{nmol} / \mathrm{m}^{2}\right.$ per $\left.24 \mathrm{~h}\right)$ & $145.8 \pm 8.8$ & $279.6 \pm 24.2$ & 0.001 \\
Hyperglycemic clamp study & & & \\
Insulin & $83.0 \pm 9.1$ & $228.1 \pm 39.3$ & 0.003 \\
C-peptide & $2.2 \pm 0.12$ & $3.6 \pm 0.48$ & 0.01 \\
Glucose & $299.0 \pm 1.2$ & $299.6 \pm 0.8$ & 0.8 \\
Secretion (nmol/m $\mathrm{m}^{2}$ per & & & \\
$\quad 180$ min $)$ & $57.2 \pm 2.8$ & $102.2 \pm 10.8$ & 0.001 \\
& & & \\
\hline
\end{tabular}

* During the 24-h meal sampling study and hyperglycemic clamp.

To convert insulin from picomoles to microunits, multiply by 145 .

much insulin as the normal controls (Table I). The relationship between insulin secretion and obesity was investigated by studying the regression relationship between the insulin secretion rate and body mass index. As shown in Fig. 2, under basal conditions (top) as well as over the 24-h sampling period (bottom), there was a statistically significant increase in the amount of insulin secreted with increasing body mass index. Of interest is the observation that the normal and obese subjects fall along the same regression line in each case.

Basal hepatic insulin extraction. As shown in Table I, basal insulin concentrations were significantly increased in the obese subjects as compared with the normal controls $(15.9 \pm 2.2$ vs. $8.2 \pm 0.5 \mu \mathrm{U} / \mathrm{ml}, P<0.003)$. The posthepatic delivery rate of
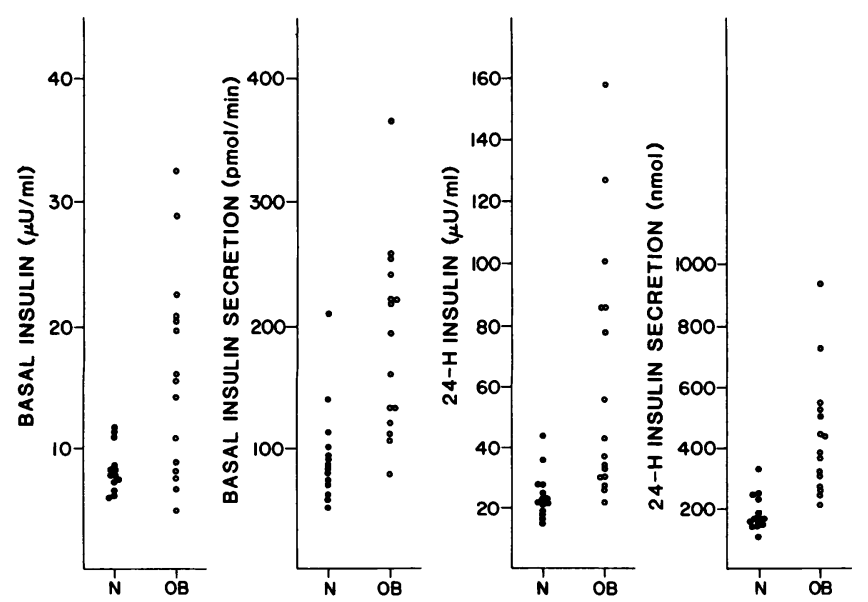

Figure 1. Individual values for the normal (N) and obese (OB) subjects are shown for basal insulin levels, basal insulin secretion rates, as well as for mean insulin levels and secretion rates during the 24-h sampling study.
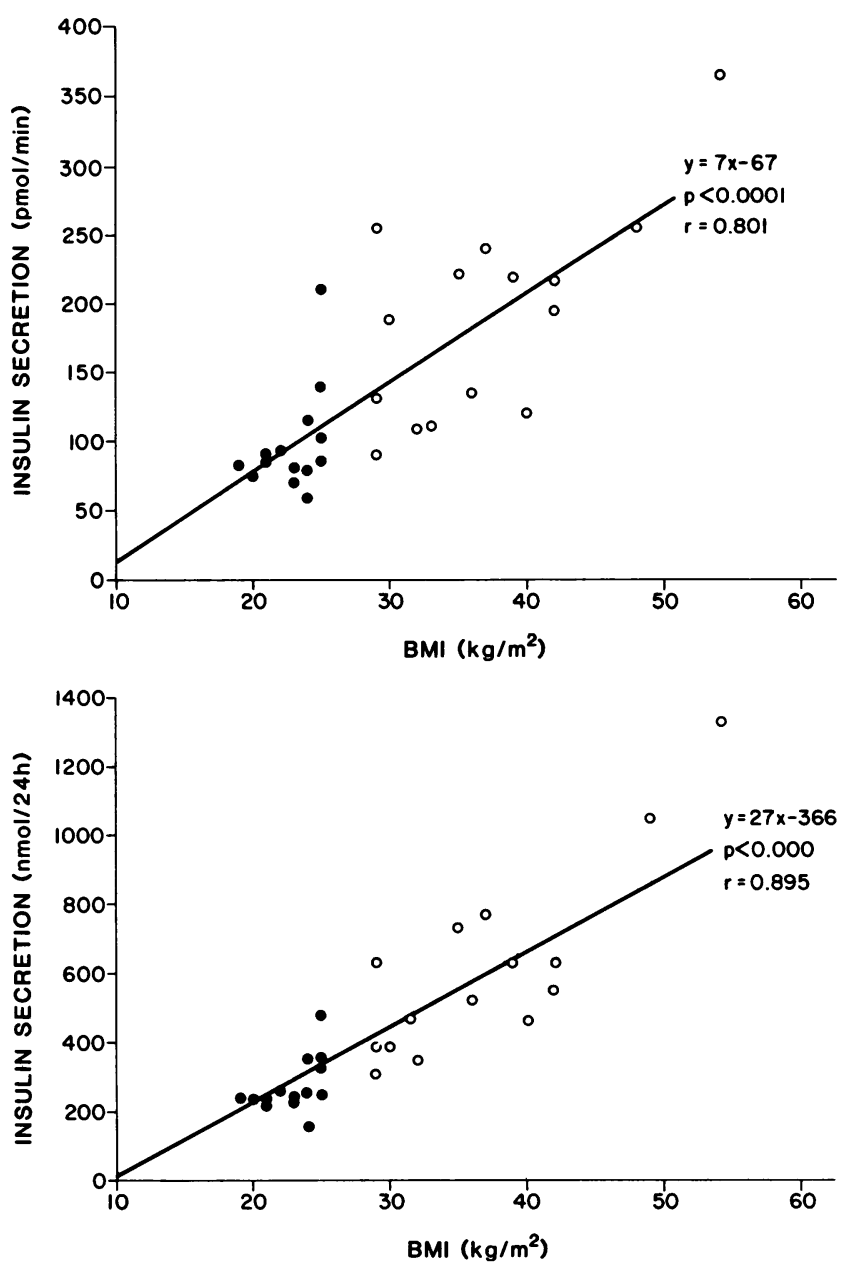

Figure 2. The relationship between body mass index (BMI) and basal (top) or total 24-h insulin rates (bottom) in the normal (solid circles) and obese (open circles) subjects.

insulin was significantly increased in the obese group (94.2 \pm 13.6 vs. $42.2 \pm 4.0 \mathrm{pmol} / \mathrm{min}, P<0.002)$. The overweight subjects also demonstrated basal insulin secretion rates that were greater than normal $(189.0 \pm 19.9$ vs. $94.9 \pm 10.8$ $\mathrm{pmol} / \mathrm{min}, P<0.001)$. However, the secretion and posthepatic delivery of insulin were increased to the same degree in the obese group, and, therefore, the calculated hepatic insulin extraction for the group means was not significantly different from normal in the obese subjects $(53.1 \pm 3.8$ vs. $51.6 \pm 4.0 \%, P$ $<0.8$ ).

To gain insight into the factors that influence basal insulin concentrations, the relationship between insulin secretion and the fasting peripheral insulin level (calculated as the mean of plasma levels in the 3-h period before breakfast) was studied. In both the normal and obese groups, fasting insulin concentrations were significantly correlated with basal insulin secretion rates $(r=0.79, P<0.003$, and $r=0.82, P<0.001$, respectively). In the normal subjects, no significant correlation between hepatic insulin extraction and the basal insulin level was observed $(r=0.11, P<0.7)$. However, in the obese subjects, there was a significant negative correlation between these two variables $(r=-0.63, P<0.02)$. In this regard, it was observed that six of the obese subjects had basal insulin concentrations within the range found in the normal subjects $(<11 \mu \mathrm{U} / \mathrm{ml})$, while nine had values above this normal range. 
The subjects with elevated insulin values had significantly lower hepatic insulin extraction than the subjects with normal basal insulin concentrations $(61 \pm 3$ vs. $45 \pm 6 \%, P<0.05)$. Although insulin secretion rates were elevated in both groups, the obese subjects with elevated basal insulin secreted more insulin under fasting conditions $\left(100.5 \pm 8.1\right.$ vs. $66.0 \pm 7.0 \mathrm{pmol} / \mathrm{m}^{2}$ per min, $P<0.05$ ) and over the 24 -h sampling period $\left(317.7 \pm 33.2\right.$ vs. $222.4 \pm 18.6 \mathrm{nmol} / \mathrm{m}^{2}$ per $\left.24 \mathrm{~h}, P<0.05\right)$ than obese subjects with normal basal insulin.

Relationship between the secretion rate of insulin and peripheral insulin concentrations during the 24- $h$ meal sampling study. To determine if insulin clearance mechanisms in general and hepatic insulin extraction in particular were different in the normal and obese subjects during the 24-h meal study, the relationship between the secretion rate of insulin and the peripheral insulin concentration during this study was examined. Normal subjects secreted $270.6 \pm 22.1 \mathrm{nmol}(145.5 \pm 8.8$ $\mathrm{nmol} / \mathrm{m}^{2}$ ) insulin over the $24-\mathrm{h}$ period as calculated by the area under the secretion rate curve. The corresponding area under the peripheral insulin concentration curve was $208.8 \pm 18.2$ $\mathrm{pmol} / \mathrm{ml}$ per $24 \mathrm{~h}$. Both the total insulin secreted $(622.7 \pm 71.9$ $\mathrm{nmol}$ in $24 \mathrm{~h})$ and insulin area $(578 \pm 102 \mathrm{pmol} / \mathrm{ml}$ per $24 \mathrm{~h})$ were significantly elevated in the obese subjects. Under these conditions as well, however, the peripheral insulin area was increased in proportion to the increase in the insulin secretion rate, and thus the ratio of the area under the secretion rate curve to the area under the insulin concentration curve was similar in the two groups of subjects $(1,340 \pm 82$ vs. $1,279 \pm 122$ $\mathrm{ml} / \mathrm{min}, P<0.7$ ). In the normal subjects, this ratio did not correlate with either the average fasting or 24-h insulin concentration. However, in the obese subjects, a significant negative correlation between the ratio and the average basal $(r$ $=-0.75, P<0.001)$ or $24-\mathrm{h}$ insulin concentration $(r=-0.74$, $P<0.002$ ) was observed, providing additional evidence that reduced insulin clearance may be present in more severely hyperinsulinemic obese subjects.

Relationship between pancreatic insulin secretion and peripheral concentrations of insulin and C-peptide during the hyperglycemic clamp (Fig. 3). During the hyperglycemic glucose infusion, insulin secretion rates increased progressively from basal levels to reach peak values of $1,554 \pm 219$ and $689 \pm 44$ $\mathrm{pmol} / \mathrm{min}$ at the end of the clamp in the obese and normal subjects, respectively (Fig. 3). During the same time interval, peripheral C-peptide and insulin concentrations also increased progressively to reach peak values of $2.91 \pm 0.17 \mathrm{pmol} / \mathrm{ml}$ and $130.4 \pm 13.7 \mu \mathrm{U} / \mathrm{ml}$ in the normals and $5.22 \pm 0.80 \mathrm{pmol} / \mathrm{ml}$ and $362.0 \pm 74.7 \mu \mathrm{U} / \mathrm{ml}$ in the obese subjects (Fig. 3).

To define the relationship between the increase in the secretion rate of insulin and peripheral concentrations of C-peptide and insulin, the insulin and C-peptide concentrations and insulin secretion rates (at each sampling time during the studies) were expressed in relation to their basal levels before starting the intravenous glucose infusion. These data are shown in Fig. 4. In the normal volunteers at the final sampling time, insulin secretion had increased to reach a level that was $6.2 \pm 0.5$ times the level in the baseline. In the obese, the corresponding relative increase was similar to normal, i.e., $5.8 \pm 0.7$ times the basal secretion rate $(P<0.7)$. As can be seen in Fig. 4 , as the insulin secretion rate increased, peripheral C-peptide concentrations increased relatively less than the insulin secretion rate. However, after 120 to $135 \mathrm{~min}$, the peripheral Cpeptide had increased to the same extent as the secretion rate
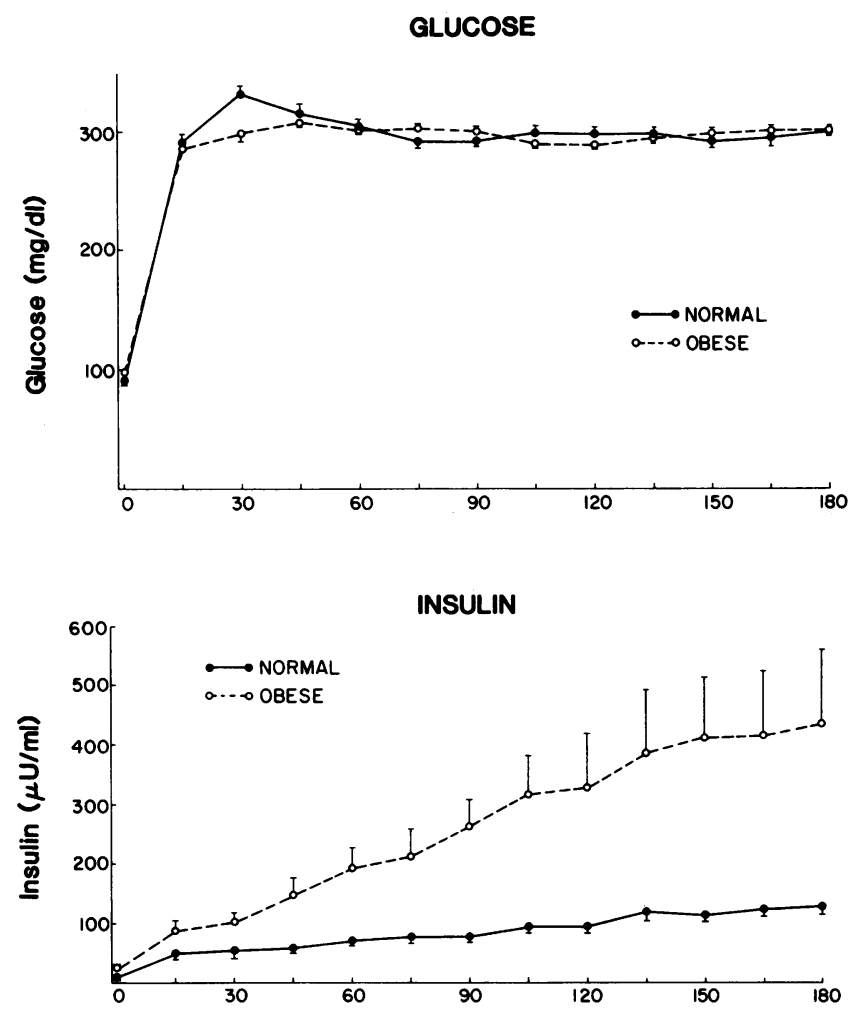

C-PEPTIDE

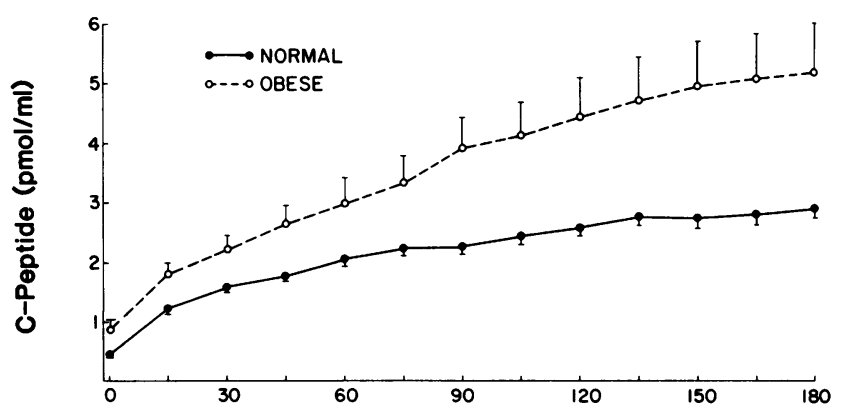

INSULIN SECRETION

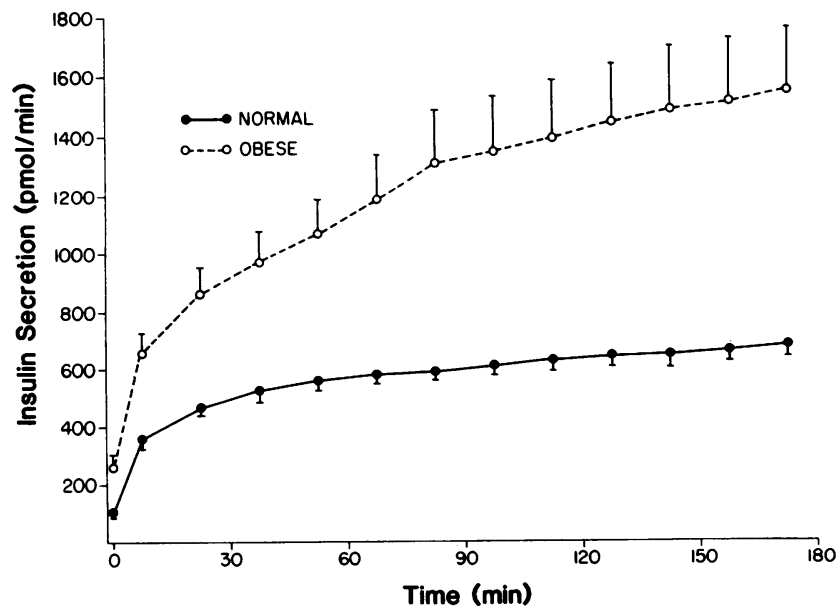

Figure 3. Concentrations of glucose, insulin, and C-peptide as well as insulin secretion rates measured during the hyperglycemic clamp in the normal and obese subjects. 

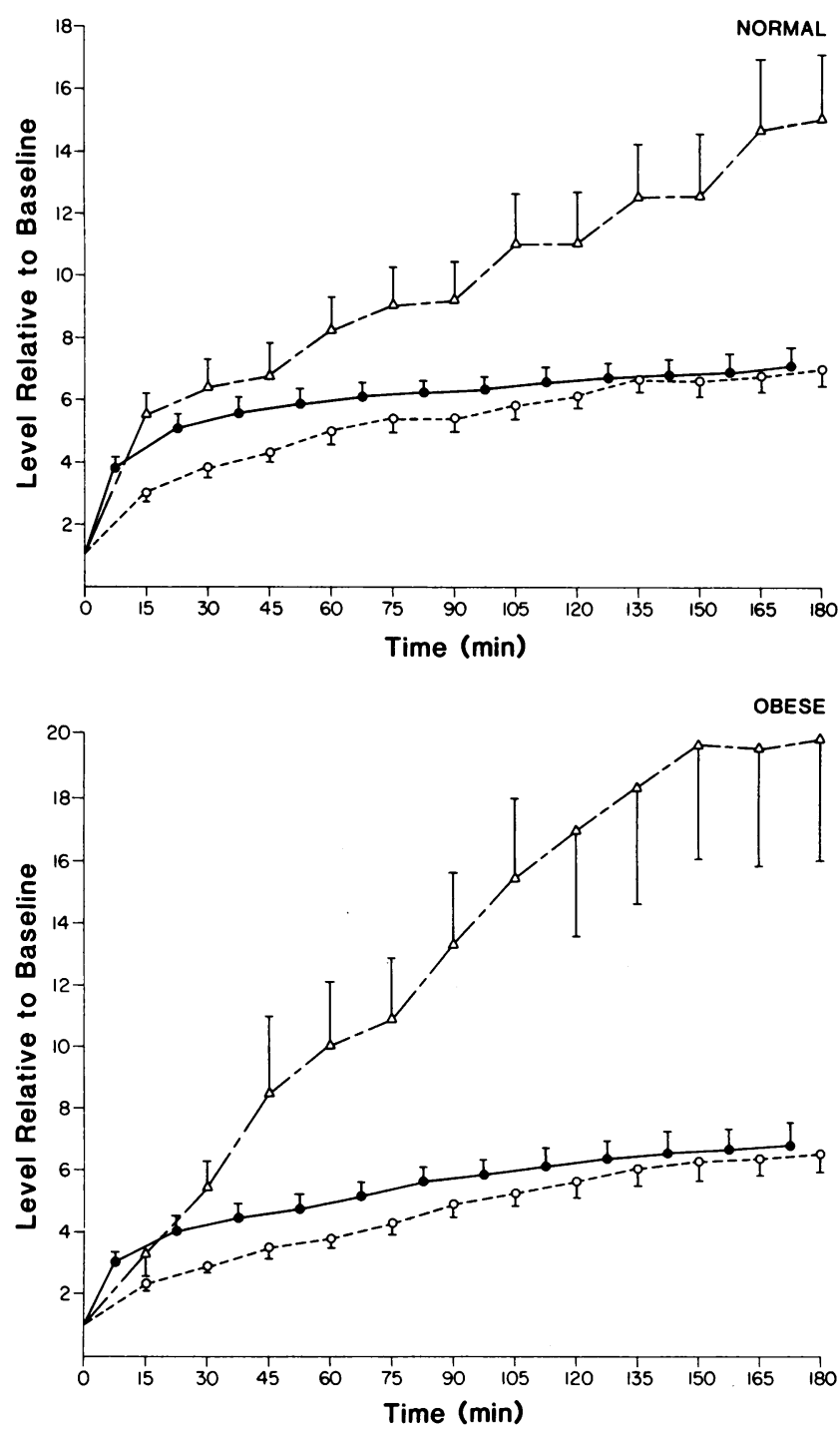

Figure 4. The relationship between changes in pancreatic insulin secretion ( $\bullet$ ) and peripheral concentrations of insulin $(\Delta)$ and C-peptide (O) during the hyperglycemic clamp in the normal (top) and obese (bottom) subjects. At each sampling time during the study the concentration of insulin or C-peptide or the insulin secretion rate was expressed as a ratio of the respective concentration or secretion rate before starting the glucose infusion. This enabled the changes in each of these parameters in relation to the basal level to be depicted.

and, at the end of the glucose infusion, had reached a level corresponding to $6.0 \pm 0.5$-fold the basal C-peptide level, an increment similar to the increment in insulin secretion. The same relationship was found in the obese subjects, i.e., over the course of the glucose infusion, insulin secretion and peripheral C-peptide levels increased to reach peak levels, which were $5.8 \pm 0.7$ and $5.0 \pm 0.6$ times their respective basal levels. In contrast, the increase in peripheral insulin concentrations was considerably greater than the increase in the insulin secretion rate in both groups. Thus, $180 \mathrm{~min}$ after beginning the glucose infusion, the basal peripheral insulin concentration had increased 14.1 \pm 2.1 -fold in the normal subjects and 16.6 3 .1fold in the obese subjects. In both groups, in response to the glucose infusion, peripheral insulin concentrations increased to a significantly greater extent than the insulin secretion rate $(P<0.004)$. Although the increment in insulin concentrations tended to be greater than normal in the obese subjects, the differences between normals and obese were not statistically significant. Additionally, peripheral insulin concentrations continued to increase even after insulin secretion rates had started to level off. Thus, in the normal volunteers, in the final $2 \mathrm{~h}$ of the glucose infusion, the insulin secretion rate increased by $<20 \%$ from $582 \pm 35 \mathrm{pmol} / \mathrm{min}$ to reach a maximum of $689 \pm 44 \mathrm{pmol} / \mathrm{min}$ at the completion of the glucose infusion. Over the same time interval the peripheral insulin concentration almost doubled from $72 \pm 9$ to $130 \pm 14 \mu \mathrm{U} / \mathrm{ml}$.

\section{Discussion}

A number of studies have ascribed the hyperinsulinemia of obesity to an increase in insulin secretion $(1,3,5)$. On the other hand, it has also been suggested that diminished insulin clearance is an important underlying mechanism for the hyperinsulinemia found in these patients $(2,4,6,7)$. Standard measurements of insulin, C-peptide, and of the C-peptide/insulin molar ratio do not allow the relative importance of hypersecretion and diminished clearance to be determined accurately (8).

In the present study, we have applied a more quantitative approach to the measurement of insulin secretion in normal and obese volunteers. This technique, which involves the application of a two-compartment model to the analysis of peripheral C-peptide concentrations and the use of individual kinetic parameters of C-peptide, allows the secretion rate of insulin to be accurately quantitated even under non-steady state conditions (9-11).

Under basal conditions, normal volunteers secreted $50.9 \pm 4.8 \mathrm{pmol} / \mathrm{m}^{2}$ per $\mathrm{min}$, and over a $24-\mathrm{h}$ period on a mixed diet $145.8 \pm 8.8 \mathrm{nmol} / \mathrm{m}^{2}$ insulin was secreted by the pancreas. These estimates of basal secretion agree closely with data previously published by ourselves and other investigators $(9,10$, $18,19)$. Estimates of stimulated insulin production rates have varied widely in previous studies, probably because none have used individually derived rate constants, as was possible in the present study $(3,9,18-20)$.

The current study clearly demonstrates that insulin secretion is increased in obesity under basal conditions, over a 24-h period on a mixed diet and in response to intravenous glucose. A highly significant linear relationship was found between both basal and 24-h insulin secretion and body mass index, which indicated that insulin secretion increases as the degree of obesity increases. Moreover, hypersecretion of insulin appears to be the most important factor in the pathogenesis of the hyperinsulinemia of obesity. Thus, the basal insulin concentration was highly correlated with the basal insulin secretion rate in both normal and obese subjects. Similarly, significant correlations were observed between the average insulin concentration during the 24-h sampling study and the total 24-h insulin production rate.

When group means for insulin metabolic clearance and hepatic insulin extraction were compared, obese subjects did not differ significantly from normal. However, more detailed examination of the data revealed that nine obese subjects with basal hyperinsulinemia $(>11 \mu \mathrm{U} / \mathrm{ml})$ had significantly lower hepatic insulin extraction than six subjects with normal fasting insulin levels $(45 \pm 6$ vs. $61 \pm 3 \%, P<0.05)$. Insulin secretion rates were elevated to a greater extent in the obese subjects with basal hyperinsulinemia. A prospective study in a larger 
group of subjects will be necessary to determine if obese subjects can be divided into the discrete groups (with normal or elevated basal insulin), or if this apparent subdivision really represents the two ends of a continuum. In the normal subjects, there was not a significant correlation between the basal insulin level and basal hepatic insulin extraction. However, in the obese subjects, a significant negative correlation was observed between these two variables $(r=-0.64, P<0.02)$. These data therefore suggest that, under normal circumstances, insulin secretion is the major determinant of the basal insulin concentration. In obesity however, reduced hepatic insulin extraction may play a contributory role in subjects with more marked hyperinsulinemia. A recent study (21) documented a reduction in the metabolic clearance rate of insulin with increasing body mass index and also concluded that reduced clearance may contribute to the hyperinsulinemia of obesity.

There is currently considerable data in the literature to indicate that insulin clearance varies under different physiological circumstances, particularly in response to ingestion of glucose by mouth (22-24). In the present $24-\mathrm{h}$ study, the areas under the peripheral insulin concentration and insulin secretion curves were calculated in the normal and obese subjects, and the ratio between these areas was calculated. This ratio provides an overall measure of endogenous insulin clearance but does not allow transient changes in insulin clearance to be detected. In fact, the units of this ratio are milliliters per minute, which represents the units of clearance. By this measure as well, overall clearance of endogenously secreted insulin was similar in the normal and obese subjects $(1,340 \pm 82$ vs. $1,279 \pm 122 \mathrm{ml} / \mathrm{min}$ ).

Analysis of the data from the hyperglycemic clamp study provided clear evidence for a reduction in insulin clearance in both normal and obese subjects at the high insulin levels in response to the glucose infusion. The present techniques do not allow us to determine if this change occurred at hepatic or nonhepatic sites. Nevertheless, the most likely explanation for this finding is that it resulted from saturation of hepatic insulin uptake. It is well known that insulin clearance saturates as the plasma insulin concentration increases (25-27). When insulin is administered via the peripheral route, most evidence indicates that saturation occurs at plasma concentrations well above the physiological range (25), although some studies have reported saturation within the physiological range $(26,27)$. In the present study, peak peripheral insulin concentrations of $130 \pm 14$ and $363 \pm 75 \mu \mathrm{U} / \mathrm{ml}$ were measured in the normal and obese subjects, respectively, during the intravenous glucose infusion. Under these circumstances, portal insulin concentrations would be expected to be three- to fourfold greater than the peripheral concentration, well within the range where saturation of clearance mechanisms may occur. Taken in conjunction with previous evidence that indicated that intravenous glucose per se does not affect insulin clearance (24), the observed reduction in clearance can be assumed to be due to the extent of the elevation in serum insulin. Another possible mechanism for this observation relates to the recent demonstration that after receptor mediated endocytosis, a proportion of the internalized insulin undergoes rapid exocytosis and is not degraded (28). An increase in the rate of this process, which has been termed retro-endocytosis, could result in the observed findings. Whatever the mechanism for the reduction in insulin clearance, the data clearly demonstrate that after stimulation of endogenous insulin secretion, insulin clearance kinetics may be nonlinear at concentrations within the high physiological range. This finding must be taken into account in attempting to derive the posthepatic delivery rate of insulin from peripheral concentrations, since kinetic parameters derived under basal circumstances may not apply after stimulation of secretion. These data also underscore the concern that data on insulin clearance derived during steady state peripheral infusions of the hormone may not apply to the physiological intraportal route of insulin delivery under non-steady state conditions.

In summary, therefore, the availability of quantitative estimates of insulin secretion has allowed several important conclusions to be drawn concerning insulin secretion and clearance kinetics in normal and obese subjects. These are $(a)$ Insulin secretion is increased in obesity and is the most important factor in the pathogenesis of the hyperinsulinemia observed in that condition. (b) Although group means for insulin metabolic clearance rate and hepatic insulin extraction are not significantly different in normal and obese subjects, diminished insulin clearance may be a contributory factor in subjects with more marked hyperinsulinemia. (c) In response to a hyperglycemic glucose infusion a reduction in insulin clearance occurs in normal and obese subjects.

\section{Acknowledgments}

The authors wish to thank Annette Miller, R.N., for expert care of the subjects who participated in the study, and Virginia Kuvakos, for secretarial assistance. The authors also wish to acknowledge the invaluable and unselfish support of Dr. A. H. Rubenstein.

This study was supported in part by grant DK-31842 from National Institutes of Health (NIH), and by grants from Eli Lilly \& Co., by the Diabetes Research and Training Center (DK-20595), and the Clinical Research Center at the University of Chicago (RR-00055). Dr. Polonsky is the recipient of a Research Career Development Award from NIH (DK-01342).

\section{References}

1. Kissebah, A. H., N. Vydelingum, R. Murray, D. J. Evans, A. J. Hartz, R. K. Kalkhoff, and P. W. Adams. 1982. Relation of body fat distribution to metabolic complications of obesity. J. Clin. Endocrinol. Metab. 54:254-260.

2. Peiris, A. N., R. A. Mueller, M. F. Struve, G. A. Smith, and A. H. Kissebah. 1986. Splanchnic insulin metabolism in obesity: influence of body fat distribution. J. Clin. Invest. 78:1648-1657.

3. Meistas, M. T., M. Rendell, S. Margolis, and A. A. Kowarski. 1982. Estimation of the secretion rate of insulin from the urinary excretion rate of $\mathrm{C}$-peptide study in obese and diabetic subjects. Diabetes. 31:449-453.

4. Faber, O. K., K. Christensen, H. Kehlet, S. Madsbad, and C. Binder. 1981. Decreased insulin removal contributes to hyperinsulinemia in obesity. J. Clin. Endocrinol. Metab. 53:618-621.

5. Savage, P. J., E. V. Flock, M. E. Mako, P. M. Blix, A. H. Rubenstein, and P. H. Bennett. 1979. C-peptide and insulin secretion in Pima Indians and Caucasians: constant fractional hepatic extraction over a wide range of insulin concentrations and in obesity. J. Clin. Endocrinol. Metab. 48:594-598.

6. Rossell, R., R. Yomis, R. Casamitjana, R. Segura, E. Vilardell, and F. Rivera. 1983. Reduced hepatic insulin extraction in obesity: relationship with plasma insulin levels. J. Clin. Endocrinol. Metab. 56:608-611.

7. Bonora, E., I. Zavaroni, C. Coscelli, and N. Butturini. 1983. Decreased hepatic insulin extraction in subjects with mild glucose intolerance. Metab. Clin. Exp. 32:438-446. 
8. Polonsky, K. S., and A. H. Rubenstein. 1984. C-peptide as a measure of the secretion and hepatic extraction of insulin. Pitfalls and limitations. Diabetes. 33:486-496.

9. Eaton, R. P., R. C. Allen, D. S. Schade, K. M. Erickson, and J. Standefer. 1980. Prehepatic insulin production in man: kinetic analysis using peripheral connecting peptide behavior. J. Clin. Endocrinol. Metab. 51:520-528.

10. Polonsky, K. S., J. Licinio-Paixao, B. D. Given, W. Pugh, P. Rue, J. Galloway, T. Karrison, and B. Frank. 1986. Use of biosynthetic human C-peptide in the measurement of insulin secretion rates in normal volunteers and type I diabetic patients. J. Clin. Invest. 77:98105.

11. Polonsky, K. S., B. Frank, W. Pugh, A. Addis, T. Karrison, P. Meier, H. Tager, and A. H. Rubenstein. 1986. The limitations and valid use of C-peptide as a marker of the secretion of insulin. Diabetes. 35:370-386.

12. Morgan, C. R., and A. Lazarow. 1963. Immunoassay of insulin: two antibody systems. Plasma insulin levels of normal subdiabetic and diabetic rats. Diabetes. 12:115-126.

13. Faber, O. K., C. Binder, L. Markussen, L. G. Heding, V. K. Naithani, H. Kuzuya, P. M. Blix, D. L. Horwitz, and A. H. Rubenstein. 1978. Characterization of seven C-peptide antisera. Diabetes. 27:170-177.

14. Frank, B. H., J. M. Pettee, R. E. Zimmerman, and P. J. Burek. 1981. The production of human proinsulin and its transformation into human insulin and C-peptide. In Peptides, Structure and Biological Function. N. A. Rich and E. Gross, editors. Pierce Chemical Co., Rockford, IL. 729-738.

15. Cleveland, W. S. 1979. Robust locally weighted regression and smoothing scatterplots. J. Am. Stat. Assoc. 74:829-836.

16. Polonsky, K., B. D. Given, W. Pugh, J. Licinio-Paixao, J. E. Thompson, T. Karrison, and A. H. Rubenstein. 1986. Calculation of the systemic delivery rate of insulin in normal man. J. Clin. Endocrinol. Metab. 63:113-118.

17. Metzler, C. M. 1971. Usefulness of the two-compartment open model in pharmacokinetics. J. Am. Stat. Assoc. 66:49-53.
18. Waldhausl, W., P. Bratusch-Marrain, S. Gasic, A. Korn, and P. Nowotny. 1979. Insulin production rate following glucose ingestion estimated by splanchnic C-peptide output in normal man. Diabetologia. 17:221-227.

19. Eaton, R. P., R. C. Allen, and D. S. Schade. 1983. Hepatic removal of insulin in normal man: dose response to endogenous insulin secretion. J. Clin. Endocrinol. Metab. 56:1294-1300.

20. Meistas, M. T., Z. Zadik, S. Margolis, and A. A. Kowarski. 1981. Correlation of urinary excretion of C-peptide with the integrated concentration and secretion rate of insulin. Diabetes. 30:639-643.

21. Davidson, M. B., M. D. Harris, and C. S. Rosenberg. 1987. Inverse relationship of metabolic clearance rate of insulin to body mass index. Metab. Clin. Exp. 36:219-222.

22. Kaden, M., P. Harding, and J. B. Field. 1973. Effect of intraduodenal glucose administration of hepatic extraction of insulin in the anesthetized dogs. J. Clin. Invest. 52:2016-2028.

23. Madsbad, S., H. Kehlet, J. Hilsted, and B. Tronier. 1983. Discrepancy between plasma C-peptide and insulin response to oral and intravenous glucose. Diabetes. 32:436-438.

24. Ishida, T., Z. Chap, J. Chan, R. Lewis, C. Hartley, M. Entman, and J. B. Field. 1983. Differential effects of oral peripheral intravenous and intraportal glucose on hepatic glucose uptake and insulin and glucagon extraction in conscious dogs. J. Clin. Invest. 72:590-601.

25. Ferrannini, E., J. Wahren, O. K. Faber, P. Felig, C. Binder, and R. A. DeFronzo. 1983. Splanchnic and renal metabolism of insulin in human subjects. A dose response study. Am. J. Physiol. 244:E517E527.

26. Sonksen, P. H., C. V. Thompkins, M. C. Srivastava, and J. D. N. Nabarro. 1973. A comparative study on the metabolism of human insulin and porcine proinsulin in man. Clin. Sci. Mol. Med. 45:633-654.

27. Morishima, T., C. Bradshaw, and J. Radziuk. 1985. Measurement using tracers of steady-state turnover and metabolic clearance of insulin in dogs. Am. J. Physiol. 248(Endocrinol Metab. II):E203-E208.

28. Levy, J. R., and J. M. Olefsky. 1986. Retroendocytosis of insulin in rat adipocytes. Endocrinology. 119:572-579. 